\title{
The Impact of the Pandemic Covid-19 on the Student's Learning Process
}

\author{
Marsela Shehu \\ PhD, Sports University of Tirana, Faculty of Movement \\ Science, Department of Social Science and Education
}

\section{Abstract}

The worldwide pandemic situation faced by the education sector presented unprecedented challenges for teachers and students in every subject, in particular, PE teachers. The teaching process was transformed from open environments, practical field instructions, to those of online platforms, with virtual instructions and demonstrations. The aim of the study is to present a theoretical overview of the online teaching of the PE subject, as well as evidence of the level of motivation and involvement of students in online teaching not only in theoretical but also practical subjects. The methodology of the study is based on a review of recent scientific articles, as well as a meta-analysis of the current situation on student involvement in online teaching, conducted and obtained from a recent quantitative database on the psychological and pedagogical aspects of online teaching. From a theoretical point of view, some researchers approve of the fact that to help teachers conceive the integration of online PE teaching with the comprehensive school curriculum of this subject, it is assumed that PE programs based on standards can serve to promote PA for all young people in school, community and home environments with the support of online teaching tools. From the quantitative data obtained from the current situation, it results that most students have had easily accessible access to these online platforms, especially in theoretical subjects. As conclusion affirms that due to the close cooperation online learning for most students in Albanian universities was easily applicable to any school curriculum.

Keywords: COVID-19, online learning, physical education, teacher, student, online platforms

\section{Introduction}

The pandemic situation all over the world exacerbated the administrative, health, educational functioning in all key sectors of every European, Balkan and Albanian country. Mostly the COVID-19 pandemic has presented unprecedented challenges for teacher education around the world. In particular, physical education teacher education (PETE) may well suffer the most in the transition from the well-established face to face instruction and environments to virtual (online) ones. [1] As a new way of teaching and learning, online learning was selected as one of the most appropriate methodologies in acquiring knowledge from students, which unquestionably required cooperation between the most important educational partners, that of teachers/lecturers and students too. [2] Considering the fact that, online learning in practically in the most Albanian public and non-public universities was a new innovation, the aim of my study is to present a theoretical overview about online teaching of the PE subject, 
as well as an evidence of the level of motivation and involvement of students in online teaching not only in theoretical but also practical subjects. The objectives of my study are to identify the level of student involvement in online learning, access and adaptation to this type of methodology, benefits and negative aspects of online learning. Critical analysis of the real situation in Albanian universities, scientific is arguments are based on my recent studies on online learning and student's motivation.

\section{Literature Review}

The COVID-19 pandemic has come to exterminate lives, dismantle projects, damage economies and above all has come to challenge human intelligence. As a method of compensation and development, even in times of quarantine, physical culture and sports are launched. Projects are undertaken to intensify and extend physical exercises to all possible territories through Information Technologies (ICTs). Teleeducation and virtual Physical Education become an effective tool to contribute to the quality of life of people in conditions of isolation and social distance. The didactics of Physical Education (PE) is turned to the discovery of new methods and strategies to reach more people in the best way. [8]

Chunlei Lu, Joe Barrett, Olivia Lu (2020) in their study, discuss the specific challenges and solutions for teaching physical education through online learning. They affirm that in PETE planning and delivery, there exists an interwoven relationship between space (e.g., requirement for and use of large activity space), equipment (exploration and use of a variety of equipment), and student engagement in physical movement and movement explorations in groups, all of which serve to make PE teaching and learning more accessible and meaningful. [1] The authors addressed unexplored yet anticipated major challenges particular to online PETE in the COVID-19 era, challenges, which were equivalent to those faced by the Albanian education system, especially of the physical education teacher's candidate. Some of this challenges presented from the authors are:

We anticipate PETE instructors may have difficulties helping teacher candidates pedagogically conceptualize, create, and practice movement concepts, skills, and strategies utilized across a variety of physical activities (e.g., games, alternative environment activities). Our concern is that the less connected face to face environment makes it more difficult for PETE instructors to help teacher candidates explore and deconstruct their own personal experiences in PE, ones often rooted in traditional and less accessible understandings of what PE teaching and learning should look and feel like.

It will be difficult to help PETE teacher candidates navigate the relationship between theory and practice in a largely two-dimensional learning environment. The face to face setting offers three-dimensional views and experiences, embodied experiences for teacher candidates to explore the use of space, movement, and equipment in PE teaching and learning. PETE teacher candidates who are not PE majors or minors (e.g., generalists) may be left to navigate the disconnect between theory and practice a divide that would often be carefully addressed in curated, embodied three-dimensional experiences (e.g., safely and purposefully utilizing space, equipment, peers, and relationships).

Even when teacher candidates understand PE curriculum and pedagogy, it will be difficult for instructors to explain and demonstrate (and difficult for teacher candidates to observe and operationalize) how to implement and adapt PE instructional models and strategies (e.g., Easy Play), and offer teacher candidates the opportunity to explore and practice teaching physical 
activities (e.g., peer-teaching) in the required space with planned equipment for targeted curricular expectations/objectives in online settings. Compounding this challenge, we anticipate online-only teaching may uncover access/equity concerns. In particular, access to technology (e.g., reliable internet, sharing of tech within home) and in-home access to physical activity equipment may be obstacles to consistent and meaningful online PETE course participation.

Some of the solutions that the authors think in their study also serve as a reflection to improve the situation in our universities or to have them in our attention during the online learning with our students in the new academic year. These solutions are:

Instructors may utilize curated videos (e.g., ATLAS, National Board for Professional Teaching Standards) to show PETE teacher candidates what purposeful teaching and learning looks like in school PE classes. Teacher candidates should be encouraged to learn how to use animations or video games to motivate school pupils to have a variety of fun physical activities.

Instructors are encouraged to consistently and frequently utilize technology to present visual aids (e.g., MS Teams whiteboard) in order for teacher candidates to identify, explore, understand, and deconstruct movement skills, sport tactics, and teaching strategies.

Instructors may work to build a supportive and collective online course community via the use of instructional methods such as group instruction, creation of online shared forums, and through efforts to connect PETE teacher candidates to practicing PE teachers in the field beyond their institutions.

PETE instructors should form a PETE related professional learning community/network (e.g., at local, regional, provincial, national, or international levels) and take advantage of both synchronous and asynchronous technology opportunities to share expertise through the use of pre-recorded audio/video PPT/PDF on online platforms (e.g., SharePoint). Moreover, PETE instructors can leverage expertise serving as guest lecturers, or invited PE experts as guests from other institutions, schools, or communities around the world to give online live presentations or workshops.

Instructors should be mindful of the pressures and stresses associated with the unprecedented challenges in the PETE online environment. It is essential to emphasize selfcare (e.g., mindfulness) and staying positive, which may help manage both mental health and productivity for the instructor and teacher candidates. [3]

In an OECD (2020) report on "Supporting the continuation of teaching and learning during the COVID-19 Pandemic" based on the survey that assessed educational needs, priorities, implementation challenges and emerging responses, the authors affirms that we need to focus on a taxonomy of needs/resources on social, emotional and cognitive skills - to help students learn outside of school, where not only the teacher but also the parents play a key role in this support. The resources are grouped into three broad sections, according to their purpose: [4]

Curriculum Resources: These include lessons, videos, interactive learning modules and any other resources that directly support students in acquiring knowledge and skills.

Professional Development Resources: These are resources which can support teachers or parents in supporting learners, guiding them to content, developing their skills to teach remotely, or more generally augmenting their capacity to support learners now learning more independently and at home, rather than at school. 
Tools: These include tools that can help manage teaching and learning, such as communication tools, learning management systems or other tools that teachers, parents or students can use to create or access educational content. [4]

Collin A. Webster and colleagues have presented online physical education (OLPE) as a viable alternate mechanism for equitable physical activity promotion among youth in the current climate, drawing from the synergy of the Comprehensive School Physical Activity Program Framework (CSPAP) framework. To help teacher educators and researchers conceptualize the integration of OLPE with CSPAPs, it is purported that standards-based physical education programs can serve to promote physical activity for all youth in school, community, and home settings with the support of OLPE tools. Similarly, the goals and expectations for high-quality physical education instruction and delivery should apply to the development of successful OLPE platforms that strive to make physical activity programming equitable, developmentally appropriate, and equally accessible, accounting for unique factors of effective OLPE access and delivery at the student, family, school, and community levels. In this sense, OLPE, through capitalizing on the inherent interconnectedness between the schools, digital technologies, physical education, the family, the community, and the student can serve to support CSPAP goals. They affirm that a natural next step is to develop learning experiences in PETE that focus on OLPE competency building, needs assessment, and resource optimization in the family and community contexts. Concurrently, research should examine the potential for preparing P-12 school professionals (e.g., physical education teachers and teacher educators) in successful practices for OLPE delivery and assess students' learning, physical activity, and related health outcomes. [7]

\section{Critical analysis of the real situation on online learning in Albanian universities}

The immediate implementation of teaching and learning online in our country, due to pandemic circumstances, caused a "chaotic" situation throughout the education system, between academic staff/ teachers and students as well. The peculiarity of this confrontation / difficulty for all of us, was the lack of previous orientation trainings / instructions for this type of teaching, in both directions, that of both students and professors. From the data obtained in my current studies, it turns out that, thankfully, students adapted easily to technological innovations. From this point of view, being users of technological tools and their curiosity in the use and implementation of their tasks, on online platforms did not turn out to be difficult for them. An important element emphasized by them was the constant communication of the lecturer with the students, although due to the lack of technological infrastructure on the part of the students, they often had problems in the online/internet connection, as well as in their own technological skills. [5] Since that the academic programs at the Sports University of Tirana in terms of its typology contain theoretical and practical modules, where I emphasize that the practical subjects before the pandemic COVID-19 took place in gyms, thereupon the studies were focused also in students 'perceptions on online learning versus that in the auditorium. The obtained data show that the realization of the learning process through online platforms were more effective in theoretical subjects than practical ones, although teaching in auditoriums is irreplaceable, (for any type of subject/module) this for easier communication and acquisition of knowledge directly. The reason that online teaching in theoretical subjects was more easily adapted to students than practical ones is due to the fact that in the syllabi of these subjects are provided essays, individual work for students, etc. and their writing in words, as well as sending in the lecturer's email was entirely possible to be realized by them. It is important for students approved the fact that, during online learning, lecturers have 
shown understanding in the presence of students, without causing them stress or other psychological distress. [6] The studies also focused on motivating and developing the student's self-efficacy, where they believe that will receive a positive grade in this academic year subjects. According to them, the basic concepts, skills, as well as the tasks developed in this platform are in line with their expectations and syllabus. A highlighted element is the concern of students when performing an alternative test on the online Microsoft Teams platform, as well as a satisfaction and success from them when they correctly perform the task. Student's claim that, in order to be accurate in submitting tasks on this online platform, they need to work closely and consistently with each other. [2] Virtuality is a technological advance that, when put in the hands of the population, implies countless savings in resources and a valuable interaction between students. However, there are many actions that must be undertaken not only to make these resources available to students but also to prepare them to make good use of them. There is no doubt that virtual physical education was created to provide the world with physical activity and sport for all, in our hands is to make possible its mission during the COVID-19 and happily after it. [8]

\section{Conclusion and Recommendation}

Online learning and online teaching was the most effective solution in the circumstances that occurred due to COVID-19. Our students present high levels of optimism for their progressiveness in the online learning process. They easily adapted to the application of the unified online platform MS Teams, easily performing tasks and tests on this platform. Lecturer-student collaboration continues to be needed in facilitating the online learning process in order to understand the basic concepts and skills learned in the modules of this study program. Highlighting the innovations and difficulties of online learning in our public universities, I recommend adapting the syllabi of some subjects with: elements, special classes, assignments, intermediate tests or exams using digital platforms, ongoing training of academic staff regarding online teaching innovations, resources, various online platforms, etc. and also improving the infrastructure in universities to facilitate this technological innovation in our auditoriums. As Richar Jacobo Posso Pacheco and his collague affirm It is just as important to ensure that physical activity in the virtual is effective in times of COVID as in the expected deescalation. To guarantee the success of PE in times of COVID it is as indispensable to develop physical capacities as to develop thought in order to ensure human welfare. Not all countries are technologically prepared to establish a sustainable and balanced PE and to achieve this it will be necessary to involve local and national governments. [8]

\section{References}

[1] Lu. C., Barrett J. \& Lu., O. (2020). "Teaching Physical Education Teacher Education (PETE) Online: Challenges and Solutions". Brock Education, Journal of Educational Research and Practice, Vol. 29 (2) 13-17pp.

[2] Shehu, M., \& Dode, E. (2020). “Online learning and student's motivation to increase selfefficacy". Knowledge International Journal, Vol 43(2), 317 - 321pp.

[3] Lu. C., (2012). "Integrating Mindfulness into School Physical Activity Programming". Teaching \& Learning, Vol 7(1), 37-46pp.

[4] OECD (2020). "Supporting the continuation of teaching and learning during the COVID-19 Pandemic". First module. Retried at 
https://globaled.gse.harvard.edu/files/geii/files/supporting_the_continuation_of_te aching.pdf

[5] Muka, R., Shehu, M. \& Vadohej, F. (2020). "The new perspectives on adapting university syllabus to online teaching platforms. (Case study)" at the TEAVET Project, Conference Proceeding Book, ISBN: 978- 84-18490-10-1, Publisher: Servicio de Publicaciones. Universidad de León, Paper ID 23.

[6] Shehu, M., Muka, R., \& Kraja, P. (2020). "The student's perceptions of online learning versus classroom learning. (Case study)" at the TEAVET Project, Conference Proceeding Book, ISBN: 978-84-18490- 10-1, Publisher: Servicio de Publicaciones. Universidad de León, Paper ID 27.

[7] Webster A. C., D’Agostino, E., Urtel. M., McMullen. J., Culp. B., Egan A. C., \& Killian C. (2021) "Physical Education in the COVID Era: Considerations for Online Program Delivery Using the Comprehensive School Physical Activity Program Framework" Human Kinetics, Inc., Journal of Teaching in Physical Education, 40(2), 327-336pp https://doi.org/10.1123/jtpe.2020-0182

[8] Pacheco, P. J. R., Enríquez, O. M. J., Viteri, P. S., Bravo, O. A. N., \& Sotomayor, N. X. F. L. (2020). "In favor of a Virtual Physical Education in times of COVID" Revista PODIUM, 15(3), ISSN: 1996-2452 RNPS: 2148, 705-716pp. 